\title{
PSICOPEDAGOGIA E PSICOMOTRICIDADE: CONTRIBUIÇÕES AO PROFESSOR ALFABETIZADOR*
}

\author{
Cássia Bastos Pinheiro ${ }^{1}$ \\ Centro Universitário São Camilo \\ Ana Maria Garcia de Mello² \\ Centro Universitário São Camilo \\ Anita Lillian Zuppo Abed ${ }^{3}$ \\ Centro Universitário São Camilo
}

\section{RESUMO}

Este artigo aborda reflexões sobre os saberes advindos da Psicomotricidade e da Psicopedagogia para o professor alfabetizador, e especialmente ao professor da Educação Infantil. Buscou-se considerações sobre a importância das habilidades motoras para a aquisição da escrita, com objetivo de apresentar, por meio de alguns aspectos teóricos, caminhos que preparam o processo de ensino-aprendizagem da escrita durante a Educação Infantil. A Psicomotricidade e a Psicopedagogia, juntas, podem colaborar na construção de estruturas que aprimoram o desenvolvimento global da criança. Nesse sentido, este artigo apresenta alguns referenciais oferecidos pela Psicomotricidade, destacando a importância de integrar perspectivas que possam subsidiar as práticas pedagógicas na Educação Infantil para melhor preparar a aquisição da escrita pela criança.

Palavras-chave: Psicomotricidade. Psicopedagogia. Motricidade. Educação Infantil. Escrita.

\footnotetext{
* Artigo apresentado como trabalho para a conclusão do curso de Pós-graduação em Psicopedagogia no Centro Universitário São Camilo.

${ }^{1}$ Licenciada em Pedagogia pela Universidade São Judas Tadeu e pós-graduanda do Curso de Especialização em Psicopedagogia Clínica e Institucional pelo Centro Universitário São Camilo. E-mail: cassia. bastospinheiro@yahoo.com

2 Professora de Educação Física, Psicomotricista, docente do curso de Pós-graduação em Psicopedagogia do Centro Universitário São Camilo. E-mail: anamovimento@gmail.com

${ }^{3}$ Psicóloga, Psicopedagoga, Neuroeducadora, Mestre em Psicologia, docente do curso de Pós-graduação em Psicopedagogia do Centro Universitário São Camilo. E-mail: anitabed@gmail.com
} 


\title{
PSYCHOPEDAGOGY AND PSYCHOMOTRICITY: CONTRIBUTIONS TO THE LITERACY TEACHER
}

\begin{abstract}
This article addresses reflections on the knowledge arising from Psychomotricity and Psychopedagogy for the literacy teacher, and especially the kindergarten teacher. Considerations on the importance of motor skills for the acquisition of writing were sought, with the aim of presenting, through some theoretical aspects, paths that prepare the teaching-learning process of writing during the Early Childhood Education. Psychomotricity and Psychopedagogy, together, can collaborate in the construction of structures that improve the child's overall development. In this sense, this article presents some references offered by Psychomotricity, highlighting the importance of integrating perspectives that can support pedagogical practices in Early Childhood Education to better prepare the acquisition of writing by children.
\end{abstract}

Keywords: Psychomotricity. Psychopedagogy. Motricity. Kindergarten. Writing.

\section{Introdução}

Atualmente, com o avanço da tecnologia e o momento delicado da pandemia da Covid-19, ocorreram profundas mudanças no cotidiano das crianças. Com o ensino híbrido (presencial e à distância) que foi determinante para os estudos, de maneira geral o contato com os videogames, tablets, celulares e computadores têm modificado a variedade e a amplitude das experiências motoras. O convívio com crianças entre quatro e cinco anos de idade, que estão vivenciando esse momento pandêmico, demonstra dificuldades nas habilidades psicomotoras relacionadas ao desenvolvimento da escrita. Sendo assim, surgiu o interesse em refletir sobre a importância dos saberes advindos da Psicomotricidade e da Psicopedagogia para o professor alfabetizador, especialmente na Educação Infantil, buscando considerações sobre a importância das habilidades psicomotoras para aquisição da escrita.

As crianças aprendem e se expressam no mundo por meio de experiências simbólicas, vivências corporais, experiências rítmicas, gestuais, sonoras... Essas experiências ocorrem a todo momento, seja em brincadeiras, ajudando nas tarefas de casa, leituras, danças, entre tantas outras. Segundo Vygotsky (1998), para entendermos o desenvolvimento da criança, é necessário levar em conta as necessidades dela e os incentivos que são eficazes para colocá-la em ação.

O trabalho desenvolvido na Educação Infantil é muito importante para a criança, entre outros motivos porque a descoberta do corpo, dos limites e dos movimentos contribui para a construção da sua imagem corporal. Atividades pedagógicas com o olhar psicomotor são essenciais para que sejam estruturadas ações pedagógicas intencionais para colaborar com esta construção, pois durante as brincadeiras, as interações e as explorações do espaço, a criança se organiza tanto nos aspectos motor e sensorial, como no emocional e social, ampliando seus conhecimentos de mundo e de si mesma.

Considerando que, na Educação Infantil, as aprendizagens e o desenvolvimento das crianças têm como eixos estruturantes as interações e a brincadeira, assegurando-lhes os direitos de conviver, brincar, participar, explorar, expressar-se e conhecer-se, a organização curricular da Educação Infantil 
na BNCC [Base Nacional Comum Curricular] está estruturada em cinco campos de experiências, no âmbito dos quais são definidos os objetivos de aprendizagem e desenvolvimento. Os campos de experiências constituem um arranjo curricular que acolhe as situações e as experiências concretas da vida cotidiana das crianças e seus saberes, entrelaçando-os aos conhecimentos que fazem parte do patrimônio cultural (BNCC, 2017, p. 40).

As vivências práticas têm um papel fundamental, pois o professor consegue observar melhor as inter-relações e a interdependência entre as instâncias físicas, psíquicas, emocionais, culturais, biológicas, simbólicas, enfim, tudo que concorre para o desenvolvimento da criança.

A escola proporciona diversas aventuras para a criança. Ao desenhar sobre o papel sente prazer de rabiscar, de gesticular e de pertencer, o corpo inteirinho se expande no espaço, fazendo a sua primeira projeção gráfica do seu corpo sobre o papel (DERDYK, 2020). O estudo dos fatores psicomotores são bases essenciais para o desenvolvimento desse processo de projeção de si no papel, que se relaciona diretamente com a aquisição da escrita. Nesse sentido, os saberes advindos da Psicomotricidade podem contribuir para o desenvolvimento global da criança, em seus aspectos físico, afetivo, cognitivo e social, e na construção das estruturas necessárias para as ações motoras envolvidas na alfabetização.

A escrita é uma atividade de alta complexidade que envolve várias habilidades psicomotoras tais como coordenação motora fina, ajustes tônicos, organização de ordem espacial e temporal. Na Educação Infantil, as crianças se desenvolvem por meio de vivências corporais, sensoriais e perceptuais que a auxiliam para aquisições posteriores como o desenvolvimento da escrita. Segundo Fonseca (2008, p. 252):

- as experiências motoras desenvolvidas com crianças em idade escolar devem reforçar as habilidades grafo motoras, o autocontrole, o tempo de atenção, a memória viso espacial e auditivo-rítmica de curto prazo e os diferentes níveis de vigilância exigidos pelo funcionamento da sala de aula;

- os vários conteúdos das aprendizagens escolares, como os pré-requisitos da leitura, da escrita e do cálculo, devem ser incorporados diretamente nas atividades motoras e lúdicas.

A Psicopedagogia é uma área interdisciplinar que investiga o processo de ensino e de aprendizagem humana, bem como as suas dificuldades, buscando compreender as influências do meio e de todos os envolvidos (o próprio sujeito, a família, a escola, a sociedade). Em relação à atuação do psicopedagogo em âmbito escolar, envolve um olhar abrangente que colabora com a compreensão das relações que ali acontecem e a identificação/criação de recursos promotores de desenvolvimento e de aprendizagem nos alunos (BOSSA, 2019).

Nesse sentido, os conhecimentos e as práticas oferecidas pela Psicomotricidade podem ser de especial valia para os psicopedagogos e para os professores da Educação Infantil, no sentido de integrar perspectivas que possam subsidiar as práticas pedagógicas voltadas à aquisição da escrita pela criança.

O presente artigo tem o objetivo de apresentar alguns aspectos teóricos que possam lançar luzes sobre o processo ensino-aprendizagem da escrita na Educação Infantil.

Justifica-se por sua intenção de evidenciar a professores e educadores em geral, incluindo os familiares, a contribuição que os conhecimentos do olhar psicopedagógico e das práticas da psicomotricidade fornecem ao desenvolvimento da escrita na educação infantil. Poderá ser ainda mais válido para educadores encarregados da alfabetização, principalmente no tocante à escrita. 
A partir do que se encontrou na literatura, optou-se por abordar os seguintes temas: delineação dos campos da Psicopedagogia e da Psicomotricidade; a Educação Infantil na BNCC (Base Nacional Comum Curricular); o corpo e as suas experiências; o desenvolvimento motor e as condições psicomotoras para a escrita.

\section{Delineando o campo da Psicopedagogia}

A Psicopedagogia é uma área interdisciplinar que, procurando reunir investigações e entendimentos de várias ciências, busca compreender o processo de ensino-aprendizagem tanto no âmbito extraescolar como no intraescolar (GRASSI, 2013).

Historicamente, a Psicopedagogia nasceu para atender à patologia da aprendizagem, mas tem se voltado cada vez mais para uma ação preventiva, acreditando que muitas dificuldades de aprendizagem se devem a alguma inadequação da abordagem pedagógica e/ou da família (BOSSA, 2019).

Destaca-se que a base da prática psicopedagógica não é formada apenas pelo conhecimento teórico sobre a psicologia da aprendizagem, a psicologia genética, as teorias da aprendizagem, a pedagogia, as teorias da personalidade e outras áreas afins, mas está especialmente envolvida pela capacidade de associar esses conhecimentos na prática e na investigação científica do processo de aprendizagem (OLIVEIRA, 2014).

Para Gasparian (1997, apud GRASSI, 2013), a Psicopedagogia, no âmbito da intervenção no espaço escolar, está relacionada ao planejamento educacional, ao assessoramento pedagógico e ao diagnóstico institucional. O psicopedagogo se atenta para as necessidades dentro da escola, analisando os processos que incluem questões metodológicas, relacionais e socioculturais, que englobam o ponto de vista dos sujeitos, abrangendo a participação da família e da sociedade.

Com base nas observações de Gasparian (1997, p. 54-55), podemos dizer que o psicopedagogo institucional é um profissional especializado no processo de ensino-aprendizagem e suas dificuldades. Para atuar no espaço institucional, precisa considerar todos os elementos envolvidos no processo e dominar conhecimentos sobre a constituição do sujeito humano e suas variações evolutivas; como o sujeito aprende e se desenvolve; de que recursos dispõe para aprender e como aprende, como se apropria dos conhecimentos; como produz conhecimentos novos, inserido num grupo, e como se relaciona nos diversos grupos de que faz parte (GRASSI, 2013, p. 148).

As dificuldades de aprendizagem são sinais que em geral se mostram na escola, mas podem emergir de uma situação social ou familiar: "a dificuldade de aprendizagem pode, portanto, caracterizar-se como um sintoma que emerge em uma situação familiar, configurando-se a partir do não-cumprimento das funções sociais por parte de determinado sujeito, portador do sintoma" (OLIVEIRA, 2014, p.84).

$\mathrm{Na}$ atuação psicopedagógica, o psicopedagogo institucional analisa a queixa apresentada e, diante disso, o que está afetando o funcionamento da instituição e o processo de ensino-aprendizagem. Para entender esse processo, é preciso ter uma compreensão das causas e dos sinais apresentados, como também é preciso um olhar psicopedagógico direcionado ao fenômeno (OLIVEIRA, 2014).

Cada criança tem um processo de desenvolvimento diferente. Dessa forma, é fundamental que o psicopedagogo e o professor, juntos, analisem individualmente cada criança para adequar os conteúdos de acordo com as necessidades de cada um. "Todo sujeito tem a sua modalidade de aprendizagem, ou seja, meios, condições e limites para conhecer" (FERNÁNDEZ, 1991, apud BOSSA, 2019, p. 36). 
Construir um vínculo afetivo é uma condição primordial do psicopedagogo, pois o carinho, a atenção, o respeito e o acolhimento, farão com que as sugestões de intervenção sejam aceitas de forma recíproca pelos sujeitos.

[...] o olhar do psicopedagogo para as dificuldades de aprendizagem do sujeito necessita partir de uma leitura ampla, contextualizada, integrada em seus aspectos cognitivos, afetivos e sociais, familiares e motores. Um olhar que permita levantar hipóteses, formular desafios, buscar as verdadeiras causas dessas dificuldades, para só assim poder delineá-las e intervir sobre elas por meio de uma perspectiva mais promissora (BASTOS, 2015, p 31).

\section{Delineando o campo da Psicomotricidade}

A Psicomotricidade, como ciência, é entendida como um campo transdisciplinar que estuda e investiga as relações e as influências recíprocas e sistêmicas, entre o psiquismo, o corpo e a motricidade, sendo emergentes da personalidade total, singular e evolutiva que caracteriza $o$ ser humano, nas suas múltiplas e complexas manifestações biopsicossociais, afetivo-emocionais e psicosóciocognitivas (FONSECA, 2008).

A Psicomotricidade estuda o ser humano na sua totalidade, nos domínios motor, cognitivo e afetivo, e compreende o corpo como o primeiro referencial de aprendizagem. O corpo não pode ser dissociado da cognição, mas sim considerado como via de aprendizagem, e o movimento, como um facilitador e motivador para aprender (GONÇALVEZ, 2009).

Há uma relação entre os processos do aprender em que o Psicopedagogia e a Psicomotricidade dialogam entre si.

Não se concebe um psicopedagogo que trabalhe com o corpo estático e que desconheça os movimentos desse corpo no aprender. Não se concebe um psicomotricista que trabalhe com o corpo em movimento e não conheça o corpo discursivo do sujeito que aprende. É preciso que haja uma interdisciplinaridade na ação ensinar-aprender para que o sujeito que aprende seja compreendido em sua totalidade, mesmo dentro de uma abordagem específica. (COSTA, 2001, p. 7).

A BNCC destaca a importância do brincar e do jogo simbólico utilizando as múltiplas linguagens da arte, música, artes visuais, dança e teatro, sendo o corpo o grande elo comunicador de expressões, sentimentos e fonte de prazer na interação com os pares. Para Fernández (1991), em todo o processo evolutivo a aprendizagem passa pelo corpo e uma nova aprendizagem integra uma aprendizagem anterior.

O Psicomotricista é o profissional que trabalha com esse corpo que se comunica, se expressa e aprende em uma ordem hierárquica de evoluções que envolve ações e gestos motores dos mais simples, como andar, ao mais complexo, como escrever.

A Psicomotricidade tem um universo de atuação ampla, contemplando o trabalho realizado em todo o desenvolvimento humano: dos bebês à "melhor idade". O seu referencial de estudo é o corpo do homem em movimento e seus pressupostos teóricos contemplam a compreensão ao que chamamos de "fatores psicomotores" que englobam o equilíbrio, a tonicidade, a noção de corpo (imagem e esquema corporal), a lateralização e a estruturação espaço temporal.

Na Educação Infantil, a aprendizagem se constitui pelo corpo vivido, pelas experiências sensório-motoras, ajustes tônicos posturais, ampliação e refinamentos de movimentos que evoluem da coordenação motora global dos segmentos corporais maiores até a coordenação motora fina com os segmentos menores de mãos e dedos. 
Para Gonçalves (2019, p. 3), "o tempo do desenvolvimento não é marcado puramente pela idade, cronologicamente, mas sim, pelo acesso à experiência".

Nesta perspectiva, durante o desenvolvimento na Educação Infantil os conhecimentos advindos da Psicomotricidade, tem o propósito de auxiliar a criança a explorar as possibilidades de movimentos do corpo, manusear objetos, exercitar sensações e percepções, movimentar-se em grandes e variados espaços por meio do brincar e do jogo simbólico.

Assim, é possível referir que a intervenção psicomotora pode utilizar diferentes mediações, perspectivando tanto a aquisição de comportamentos motores em fundo Tonico emocional e relacional (mais intrínseca), como o desenvolvimento das capacidades relacionais, simbólicas e emocionais em fundo de vivências motoras (mais extrínseca). O que permite dizer que se está perante a psicomotricidade sem divisões, mas que pode estar associada a determinada prática, que se fundamenta nas mediações corporais necessárias para alcançar os objetivos específicos para quem se destina, tendo sempre como pano de fundo o saber da psicomotricidade operacionalizada por meio do olhar, da escuta e da intervenção do psicomotricista (FERNANDES, 2012, p. 3-4).

\section{Educação infantil na BNCC}

A BNCC, homologada em dezembro de 2017, explicita as habilidades de desenvolvimento das práticas pedagógicas na Educação Básica, que se tornaram uma diretriz em âmbito nacional. Apresenta-se como um documento normativo que define o conjunto de aprendizagens essenciais que todos os alunos devem desenvolver ao longo das etapas e modalidades da Educação Básica. Seu principal objetivo é ser a balizadora da qualidade da educação no país, por meio do estabelecimento de um patamar de aprendizagem e desenvolvimento a que todos os alunos têm direito.

A análise das dez competências gerais que asseguram o desenvolvimento e os direitos de aprendizagem em âmbito pedagógico (BNCC 2017, p. 9-10), mostra que várias habilidades integradas contemplam o conhecimento, o desenvolvimento socioemocional e o ético, destacando que essas atribuições estão presentes ao longo da escolaridade.

1. Valorizar e utilizar os conhecimentos historicamente construídos sobre o mundo físico, social, cultural e digital para entender e explicar a realidade, continuar aprendendo e colaborar para a construção de uma sociedade justa, democrática e inclusiva.

2. Exercitar a curiosidade intelectual e recorrer à abordagem própria das ciências, incluindo a investigação, a reflexão, a análise crítica, a imaginação e a criatividade, para investigar causas, elaborar e testar hipóteses, formular e resolver problemas e criar soluções (inclusive tecnológicas) com base nos conhecimentos das diferentes áreas.

3. Valorizar e fruir as diversas manifestações artísticas e culturais, das locais às mundiais, e participar de práticas diversificadas da produção artístico-cultural.

4. Utilizar diferentes linguagens - verbal (oral ou visual-motora, como Libras, e escrita), corporal, visual, sonora e digital -, bem como conhecimentos das linguagens artística, matemática e científica, para se expressar e partilhar informações, experiências, ideias e sentimentos em diferentes contextos e produzir sentidos que levem ao entendimento mútuo.

5. Compreender, utilizar e criar tecnologias digitais de informação e comunicação de forma crítica, significativa, reflexiva e ética nas diversas práticas sociais (incluindo as escolares) 
para se comunicar, acessar e disseminar informações, produzir conhecimentos, resolver problemas e exercer protagonismo e autoria na vida pessoal e coletiva.

6. Valorizar a diversidade de saberes e vivências culturais e apropriar-se de conhecimentos e experiências que the possibilitem entender as relações próprias do mundo do trabalho e fazer escolhas alinhadas ao exercício da cidadania e ao seu projeto de vida, com liberdade, autonomia, consciência crítica e responsabilidade.

7. Argumentar com base em fatos, dados e informações confiáveis, para formular, negociar e defender ideias, pontos de vista e decisões comuns que respeitem e promovam os direitos humanos, a consciência socioambiental e o consumo responsável em âmbito local, regional e global, com posicionamento ético em relação ao cuidado de si mesmo, dos outros e do planeta.

8. Conhecer-se, apreciar-se e cuidar de sua saúde física e emocional, compreendendo-se na diversidade humana e reconhecendo suas emoções e as dos outros, com autocrítica e capacidade para lidar com elas.

9. Exercitar a empatia, o diálogo, a resolução de conflitos e a cooperação, fazendo-se respeitar e promovendo o respeito ao outro e aos direitos humanos, com acolhimento e valorização da diversidade de indivíduos e de grupos sociais, seus saberes, identidades, culturas e potencialidades, sem preconceitos de qualquer natureza.

10. Agir pessoal e coletivamente com autonomia, responsabilidade, flexibilidade, resiliência e determinação, tomando decisões com base em princípios éticos, democráticos, inclusivos, sustentáveis e solidários.

Com esse enfoque, a BNCC indica que as decisões pedagógicas devem estar orientadas para o desenvolvimento das competências, fortalecendo as ações que asseguram as aprendizagens essenciais definidas e o desenvolvimento integral dos estudantes.

No que diz respeito à Educação Infantil, a proposta consiste no desenvolvimento moral, emocional, social, cognitivo e motora, que são estruturados pelos eixos das brincadeiras e das interações.

De acordo com a BNCC (2017, p. 37), deve-se ter

[...] na Educação Infantil, as condições para que as crianças aprendam em situações nas quais possam desempenhar um papel ativo em ambientes que as convidem a vivenciar desafios e a sentirem-se provocadas a resolvê-los, nas quais possam construir significados sobre si, os outros e o mundo social e natural.

Na Educação Infantil, são assegurados seis direitos de aprendizagem, para que as crianças tenham condições de aprender e se desenvolver. Os direitos de aprendizagem são definidos pela BNCC (2017, p. 25) como: Conviver, Brincar, Participar, Explorar, Expressar-se e Conhecer-se.

Considerando esses direitos de aprendizagem, são apresentados cinco campos de experiências fundamentais para o desenvolvimento da criança na Educação Infantil, a saber: 1) O eu, o outro e o nós; 2) Corpo, gestos e movimentos; 3) Traços, sons, cores e formas; 4) Escuta, fala, pensamento e imaginação; 5) Espaços, tempos, quantidades, relações e transformações. A explicitação dos objetivos está organizada em três grupos de faixa etária: Bebês (0-1 a 6 meses), Crianças bem pequenas ( 1 a 7 meses a 3 anos e 11 meses) e Crianças pequenas ( 4 anos a 5 anos e 11 meses). 
Nessa direção, e para potencializar as aprendizagens e o desenvolvimento das crianças, a prática do diálogo e o compartilhamento de responsabilidades entre a instituição de Educação Infantil e a família são essenciais (BNCC, 2017, p. 36-37).

\section{O corpo e as suas experiências}

A criança é um ser em contínuo movimento. Enquanto brinca, o seu corpo descobre e explora novas possibilidades que são importantes para a aquisição das habilidades motoras e socioafetivas. A interação entre o corpo, o movimento, o espaço e os brinquedos, ou brincadeiras que movimentam o corpo, é fundamental para a educação da criança pequena (KISHIMOTO, 2011).

Segundo Kishimoto (2011), as experiências motoras eram vivenciadas espontaneamente pelas crianças em brincadeiras na rua, junto com os amigos, formando uma base para o aprendizado das habilidades mais complexas. Porém, com as mudanças dos cenários ao longo dos anos, o brincar com o corpo passou a ser mais estimulado e desenvolvido na escola. A criança vivencia o seu corpo no mundo e conforme vai se desenvolvendo, cada pedacinho do seu corpo vai adquirindo autonomia.

O movimento é uma parte construtiva da aprendizagem e da vivência na escola. Entre os sinais gráficos de uma língua escrita e o mundo concreto, existe um mediador, às vezes esquecido, que é a ação corporal (FREIRE, 1991).

A aprendizagem da escrita será foco do Ensino Fundamental, séries iniciais, e na Educação Infantil é importante preocupar-se com o desenvolvimento das condições básicas para tal. Nesse processo, os elementos básicos da Psicomotricidade são usados com frequência: o equilíbrio, os ajustes tônicos e posturais, a lateralidade, a estrutura espacial e a orientação temporal são de suma importância. Assim, é possível referir que a intervenção psicomotora pode utilizar diferentes mediações, perspectivando tanto a aquisição de comportamentos motores em fundo Tonico emocional e relacional (mais intrínseca), como o desenvolvimento das capacidades relacionais, simbólicas e emocionais em fundo de vivências motoras (mais extrínseca) (FERNANDES, 2012, p. 3).

Todas as atividades sensório-motoras realizadas pelas crianças devem ser vivenciadas como experiências suficientemente boas, que envolvem a noção de fantasmas de ação, proveniente das experiências corporais partilhadas entre a criança e a mãe (FONSECA, 2008, p. 6-7).

\section{$\mathbf{O}$ desenvolvimento motor}

A aprendizagem da escrita está envolvida estruturalmente em várias organizações de movimentos corporais, que se reproduzem a partir de um conjunto de fatores. As competências psicomotoras são desenvolvidas ao longo da evolução de cada indivíduo, e, pouco a pouco, os domínios corporal, socioemocional e cognitivo vão estruturando a personalidade da criança (FONSECA, 2008).

O desenvolvimento motor é a base essencial para o desenvolvimento da escrita, considerando que ele é estreitamente dependente da maturação do sistema nervoso, da experiência e da prática (BOSCAINI, 1998). Pode-se, ainda, considerar dois níveis para o desenvolvimento motor:

o desenvolvimento geral - compreende o controle postural, a regulação tônica e as diversas competências motoras bem coordenadas. De fato, a escrita requer equilíbrio, controle corporal e gestão do 
tônus. O desenvolvimento da motricidade fina da mão e dos dedos; sabemos quanto são basilares todas as atividades manipulatórias para a aprendizagem da escrita. Desse ponto de vista, são também tomados em consideração todos os aspectos concernentes à coordenação óculo-manual, os quais se aperfeiçoam com o desenvolvimento perceptivo-motor (BOSCAINI, 1988, p. 43-44).

Para uma boa evolução da escrita, não se pode dispensar o aprendizado de uma boa estruturação espaço-temporal, destacando a lateralidade como orientação espacial e o ritmo gráfico.

Muitas habilidades são necessárias para que se possa escrever, entre elas, a organização do ato motor exigido na utilização dos instrumentos para a escrita e nos movimentos dos traços que compõe as letras e os números (GONÇALVES, 2014, p. 6).

\section{Condições psicomotoras para a escrita}

Quando tiver início o processo de construção da escrita, prevista para os anos iniciais do Ensino Fundamental, a criança precisará da sua mão, assim como da orientação espacial, do ritmo motor, da sua postura e do reconhecimento de seu corpo.

A função do equilíbrio é a base de tudo no ato da escrita, que aos poucos com as atividades vai evoluindo no espaço, o braço se torna um apoio móvel e dinâmico, que vai se reajustando continuamente em razão do deslocamento linear da esquerda para direita e do alto para baixo (BOSCAINI, 1998, p. 46).

Todo esse desenvolvimento para desenhar as letras seguindo sua direção espacial implica numa relação harmônica e precisa entre o controle tônico-postural e o controle tônico-motor do braço. O dinamismo postural depende do ajuste do segmento braço-mão em harmonia rítmica ao deslizar o lápis sobre a folha.

O controle motor garante a manutenção da postura e locomoção do nosso corpo, da movimentação de suas partes específicas para realizar tarefas manipulativas como a construção e uso de ferramentas e, finalmente, a de expressar nossos pensamentos e os sentimentos (GONÇALVES, 2014, p 9).

Nesse sentido, pensando no desenvolvimento e nas relações entre os elementos estáticos e dinâmicos do corpo da criança, podemos perceber que estão ligados a uma dupla gestão do movimento da lei proximodistal, que se encontram na base do controle e da organização do movimento no espaço (BOSCAINI, 1998). A lei "proximodistal" refere-se à direção do desenvolvimento psicomotor, do centro para as extremidades. Primeiro a criança se locomove com o corpo inteiro em movimento, depois percebe que esse corpo tem dois lados e por último que cada lado tem segmentos menores capazes de realizar ações específicas e refinadas, como o ato de escrever.

O perfil psicomotor representa a qualidade de comunicação entre o psíquico e o motor em um determinado momento do desenvolvimento da criança, sendo este um componente vital e de suma importância para o ato inicial da escrita (FONSECA, 2008).

O tônus também está ligado ao equilíbrio. Sua competência reguladora fina e precisa, permite a determinação do grau de controle tônico que é necessário em cada momento do percurso do braço. Sua função é entendida como uma tensão fisiológica dos músculos que garante o equilíbrio estático e dinâmico, a coordenação e a postura em qualquer posição adotada pelo corpo.

A regulação do tônus varia com a idade e está estreitamente relacionada à capacidade, por parte de quem escreve, de encontrar o justo apoio do braço: isso permite a realização das letras e das palavras na mesma dimensão e inclinação em respeito à linha (BOSCAINI, 1998). 
Outro fator importante, referindo-se à regulação tônica, é a base de uma boa preensão manual adaptada às exigências para a escrita cursiva: faz-se necessário uma rotação contínua do antebraço, em torno do cotovelo, que permanece como ponto fixo, e a preensão em pinça (Figura 1).

Figura 1. Preensão.

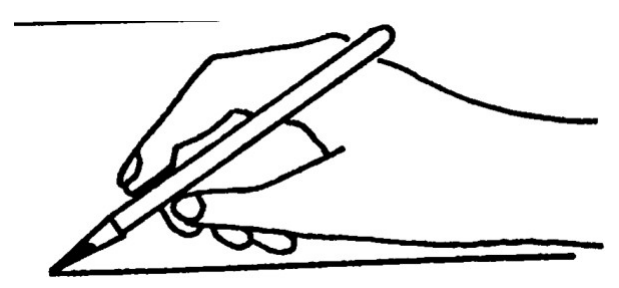

Fonte: Boscaini (1998, p. 47).

Para escrever, a criança, ao longo do seu contato com o lápis e outros instrumentos da escrita, chegará à fase ideal da preensão, porém esse desenvolvimento demanda um tempo para que os músculos dos dedos tenham força o suficiente.

A pressão é a capacidade de se imprimir uma força controlada em um objeto sobre uma base. No caso da escrita (simbólica ou pictórica) é a pressão do lápis sobre o caderno; giz na lousa; lápis de cor nas folhas de pintura; pincéis, borracha etc. Cada um dos instrumentos usados na escrita necessita de intensidades da pressão exercida diferentes (GONÇALVES, 2014, p. 13).

Esse processo deve acontecer de forma natural e para se alcançar o bom desenvolvimento, é importante que o professor de Educação Infantil e séries iniciais do Ensino Fundamental proporcione vivências que permitirão o aprimoramento motor fino (Figura 2).

Figura 2. Fases do Desenvolvimento da Preensão do Lápis.

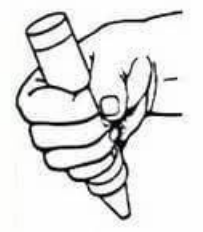

1-1.5 anos

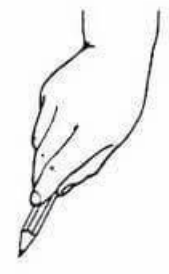

2-3 anos

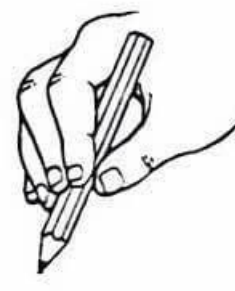

3.5-4 anos

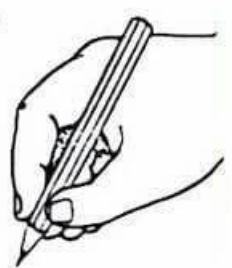

4.5-6 anos

Fonte: FASES (2021).

Quando escrevemos, as execuções motoras permitem a realização de traços orientados da esquerda para a direita. Para Isso, a criança precisa ter desenvolvido uma boa organização espaço-temporal, dominância lateral e adequada integração do esquema corporal, para percorrer o espaço da folha em linhas paralelas.

Porém, para que a criança consiga aprimorar a dominância lateral, antes de pegar no lápis para desenhar as letras, o professor de Educação Infantil poderá propiciar atividades vivenciadas com o corpo inteiro, depois atividades aprimorando a dominância lateral funcional em estreita cone- 
xão com a estruturação espacial e temporal. Esses elementos bem trabalhados auxiliam nos movimentos posteriores que demandam maior precisão motora e controle tônico, como a pega adequada no lápis e a coordenação para o desenho de letras e números.

\section{Da garatuja para a escrita}

A criança quando desenha, o faz para se divertir. Nesse momento, ela é dona de suas próprias regras. "O desenho é o palco de suas encenações, a construção de seu universo particular" (DERDYK, 2020, p. 39). Os traços, os rabiscos e as garatujas exibem uma atividade de projeção do esquema corporal da criança.

A garatuja não é simplesmente uma atividade sensório-motora, descomprometida e ininteligível. Por meio dessa aparente "inutilidade" contida no ato de rabiscar, estão latentes segredos e sensações existenciais, confidenciais, emotivas, e as necessidades de comunicação (DERDYK, 2020).

Neste sentindo, quando a criança começa a rabiscar, ela compreende que o gesto feito sobre a folha deixa um traço, uma marca do seu próprio corpo, um traço que pertence a si própria se pertencendo como resultado de sua motricidade em um espaço gráfico delimitado pelo gesto (BOSCAINI, 1998).

A excitação motora conduz a outros gestos. Já está implícita aí uma atividade mental, na medida em que a criança associa, relaciona, subtrai ou adiciona um gesto ou outro. O desenho é indecifrável para nós, mas, provavelmente, para a criança, naquele instante, qualquer gesto, qualquer rabisco, além de ser uma conduta sensório-motora, vem carregado de conteúdos e de significados simbólicas (DERDYK, 2020, p. 45).

Para a criança, a garatuja representa seu primeiro desenho sendo efetivamente a sua primeira escrita.

Para ter maior clareza e intencionalidade no planejamento pedagógico, é importante que o professor da Educação Infantil (e o psicopedagogo que porventura estiver apoiando suas ações) conheça alguns aspectos sobre a evolução da motricidade gráfica, salientando as primeiras coordenações do movimento, as regulações tônicas e o controle cinestésico e visual.

\section{As primeiras coordenações dos movimentos para o registro gráfico}

Por volta dos 10-12 meses de idade, ao pegar o lápis com toda a mão, a criança executa os seus primeiros gestos gráficos. O lápis escorrega pelo papel, resultando em uma série de movimentos impulsivos expressos por uma incontrolada descarga motora. Seus traços em zigue-zague, vai e vem ou do tipo circular, demonstram uma coordenação de movimentos que necessitam da participação de todo o corpo e não apenas do braço, pois a criança escreve com o corpo mais do que com a mão (BOSCAINI, 1998).

Nesse momento, a criança vive a magia que a estimula sensorialmente. O prazer pelos rabiscos de sua garatuja a tornam única e livre para experimentar o conhecimento das novas estruturas de movimento. Os educadores (professor e/ou psicopedagogo), ao desenvolver as práticas psicomotoras, necessitam pensar em atividades que estimulam as experiências corporais sobre a globalidade total da criança na escola. As experiências sensório-motoras, nessa fase, são vividas intensamente, de modo prazeroso, e atividades como colagem, tintas, massinha, brinquedos de 
encaixe, exploração de folhas secas, entre outras, desenvolverão uma boa coordenação relacionada a outras habilidades psicomotoras, estimulando e promovendo a maturação neuro motora necessária para o desenvolvimento da escrita.

$\mathrm{Na}$ infância contemporânea, é comum que nessa fase a criança já esteja em contato com a escola. Esta passa a ter grande papel no desenvolvimento da criança, pois a coloca em contato com um espaço social diferente, no qual todas as habilidades conquistadas até aqui serão utilizadas e aplicadas na aprendizagem de um conhecimento formal norteado pela linguagem falada e escrita (GONÇALVES, 2014, p. 18).

\section{As regulações tônicas}

A regulação tônica diz respeito ao melhor controle da intensidade de um movimento. No final do segundo ano de idade, as descargas motoras pouco a pouco se atenuam e as tentativas de controle do movimento dos ombros se integram entre tônus e movimento, e entre postura e movimento. Essa função tônica está sempre presente no gesto gráfico, intervindo na própria qualidade desse gesto por meio de modificações, facilitações ou controles. Quando acontece uma situação de descontrole tônico para a criança fica difícil manter a concentração sobre o gesto gráfico, e quando chegar o momento da escrita, isso poderá se tornar ainda mais difícil (BOSCAINI, 1998).

As regulações tônicas são complexas tanto na dimensão emocional, quanto na cognição e no movimento propriamente dito, por isso as experiências tônicas, vividas emocionalmente em relação a toda sua variante entre a tensão e a distensão, se tornam fundamentais para a integração do movimento.

Trata-se da estruturação dos centros neurológicos que cuidam das posturas, posições e gestualidade do corpo. Estrutura-se bem cedo seguindo os padrões de desenvolvimento humano, céfalo-caudal e próximo distal. Para um bom controle postural, é necessário um tônus muscular adequado que mantenha o corpo em diferentes níveis de contração e do equilíbrio, determinado pelas estruturas do cerebelo e do sistema vestibular. A partir do sistema postural integrado, a criança passa a movimentar-se cada vez mais e melhor aprende a "agir" no seu meio como os demais da sua cultura (GONÇALVES, 2014, p. 10).

\section{O controle cinestésico e visual}

Gradualmente, o controle cinestésico e visual tende a se integrar ao controle tônico, por volta dos dois anos e dois meses de idade. Nessa fase, nota-se que esse controle se torna progressivamente dominado pelo controle visual, graças ao desenvolvimento da função perceptiva (BOSCAINI, 1998).

Assim, a percepção visual se torna, juntamente com a audição e com o sentido tátil-cinestésico, um componente essencial e complementar do comportamento e da aprendizagem (FONSECA, 2008, p. 282).

A partir dos dois anos e seis meses de idade, o controle visual se torna mais preciso, gerindo todo o trabalho da mão. A evolução do grafismo só é possível à medida em que se desenvolvem todas as possibilidades de coordenação motora nos diversos segmentos do membro superior. Esse controle aos poucos se transfere de acordo com a "lei próximo-distal", e só então ocorre a separação dos movimentos da mão e dos dedos, favorecendo uma maior precisão das realizações gráficas (BOSCAINI, 1998). 
Diante dessa perspectiva, vemos o quanto a psicomotricidade salienta a importância de se viabilizar as diversas experiências sensório-motoras, que são fundamentais para o desenvolvimento da criança antes de iniciar o processo da escrita. Podemos compreender, então, que não é possível ter uma boa competência gráfica sem antes adquirir uma válida organização da motricidade em todas as suas configurações espaciais, sendo indispensável à preparação do trabalho corporal, desse modo o papel da Educação Infantil é justamente promover o desenvolvimento global da motricidade.

\section{A evolução do ato gráfico}

A organização do movimento gráfico está estritamente relacionada com o desenvolvimento da motricidade geral, mas sobretudo com a motricidade dos membros superiores. O controle progressivo dos movimentos do braço permite à criança desenvolver o próprio repertório gráfico e, então, reproduzir certas formas que se tornam a base tanto para o desenho quanto para a escrita. $O$ aparecimento progressivo dos traçados não é outro que a projeção do movimento adquirido no espaço gráfico (ou seja, sobre a folha), o produto da criança sobre a folha, sua maneira de organizar o desenvolvimento dos traços (BOSCAINI, 1998).

Dessa forma, podemos pensar que, para a criança, os atos gráficos são verdadeiros jogos grafo motores, pois representam a passagem do plano motor para o perceptivo, das condições motoras para o desenvolvimento da escrita.

Essa evolução motora, por meio dos traçados, surge graças à maturação da capacidade neuro motora da criança seguindo os critérios das leis cefalocaudal (da cabeça em direção aos pés) e proximodistal (do eixo central do corpo para as extremidades) do sistema nervoso (BOSCAINI, 1998).

Quando a criança começa a aprender a escrita, ela combina um modelo visual e um modelo cinestésico. O modelo visual é a realização de um movimento executado no espaço-tempo e é específico de cada letra; o modelo cinestésico é proposto à criança por alguém (professor ou outro) que guia a sua mão e lhe permite associar a representação da letra à automatização (BOSCAINI, 1998)

Portanto, a escrita é o resultado da associação da percepção visual da letra com o mecanismo da realização motora: sem controle dos movimentos (cinestésicos) e dos traçados (visual), não é possível a escrita.

\section{Considerações finais}

Pensando na complexidade do ato da escrita, o presente artigo abordou a importância dos conhecimentos advindos da Psicomotricidade no desenvolvimento das habilidades motoras na Educação Infantil, tema que tem sido muito discutido nos contextos educativos. No ambiente escolar, os professores organizam experiências corporais por meio das atividades psicomotoras para desenvolver e aprimorar as habilidades motoras. Nesse sentido, o psicopedagogo que trabalha com essa fase da escolarização precisa aprofundar-se na compreensão de como as práticas psicomotoras podem contribuir para um olhar e uma ação psicopedagógica que contribua com o desenvolvimento das bases para a aprendizagem da escrita.

Em relação à importância das habilidades motoras nos anos iniciais da vida das crianças, Andrade (2019, p. 89) enfatiza que: 
[...] a partir do momento em que as atividades começam a ser oferecidas em sala de aula, nota-se um progresso que repercute em todo conjunto, apesar de não ser manifestado imediatamente, os avanços registrados e observados nas diversas situações, interfere em outras e, num espaço não muito longo de tempo. Sendo assim, o que realmente importa é selecionar o maior número possível de situações que promovam o desenvolvimento de habilidades variadas, pois o objetivo é sempre a aprendizagem.

Ampliando essa reflexão, Freire e Germano (2018, p. 344) concluem que:

[...] na Educação Infantil as atividades motoras devem ser bem trabalhadas, porque quando a psicomotricidade é inserida no processo de aprendizagem da criança, percebe-se um maior desenvolvimento da comunicação, da interação, da cognição e dos seus movimentos, habilidades fundamentais para o desenvolvimento da leitura e da escrita.

Duzzi, Rodrigues e Ciasca (2013) relatam uma pesquisa de campo realizada com professoras que atuavam nos dois últimos anos da Educação Infantil e nos três primeiros anos do Ensino Fundamental I, em uma escola pública na cidade do interior de São Paulo. Por meio de resposta a um questionário, investigou-se o conhecimento dos profissionais sobre a relação entre o desenvolvimento das habilidades psicomotoras e a escrita.

Dentre os dados coletados, 18 de 33 sujeitos afirmaram que tiveram a disciplina específica sobre "Psicomotricidade a Aprendizagem" na graduação. Já na especialização, esse tópico foi visto por 14 dos 23 entrevistados. A pesquisa concluiu que há evidências de que essa abordagem foi superficial, pois as respostas demonstraram desconhecimento dos profissionais sobre o tema. Por outro lado, $75,8 \%$ dos sujeitos afirmaram que tinham conhecimento sobre a importância das funções psicomotoras para a aquisição da escrita.

Analisando essa pesquisa, pode-se supor que muitos professores de Educação Infantil não aprimoram as atividades dentro da sala de aula, por não saberem como aplicar a prática psicomotora.

Nesse sentido, ressalta-se a importância de o psicopedagogo buscar a ampliação de seus próprios conhecimentos sobre a psicomotricidade, para que possa auxiliar os professores em como desenvolver as práticas da psicomotricidade, objetivando não só a aprendizagem da escrita como também um melhor desenvolvimento corporal das crianças.

Cabe ressaltar que é preocupante o aparente desconhecimento de uma formação tão importante para o aprendizado infantil. A Pedagogia deve ser mais auspiciosa para o desenvolvimento total, motor, emocional e cognitivo da criança e do jovem, retirando-lhes as resistências que aprenderam, por sobrevivência ou por necessidade (FONSECA, 2008).

Sendo assim, a Psicomotricidade nos faz pensar em ideias que enriquecem o autoconhecimento do corpo, o que nos direciona para práticas psicopedagógicas mais completas e exploradoras. Assim, a Psicopedagogia e a Psicomotricidade estão diretamente ligadas aos processos de desenvolvimento da aprendizagem da escrita na primeira infância, pois ambas possuem uma visão interdisciplinar relacionada aos processos cognitivos, afetivos e emocionais do sujeito, buscando compreender a tomada de consciência de um corpo enquanto instrumento de conhecimento (FONSECA, 2008).

\section{Referências bibliográficas}

ANDRADE, O. T. A contribuição da psicomotricidade na aprendizagem da escrita. Cadernos da Pedagogia, v.13, n. 25, Jul/Set 2019. 
BASTOS, A. B. B. I. Psicopedagogia Clínica e Institucional: diagnóstico e intervenção. São Paulo: Edições Loyola, 2015.

BOSCAINI, F. Psicomotricidade e Grafismo: Da grafomotricidade à escrita. Rio de Janeiro: Sette Letras, 1998.

BOSSA, N. A. A Psicopedagogia no Brasil: contribuições a partir da prática. Rio de Janeiro: Wak Editora, 2019.

BRASIL. M. E. Base Nacional Comum Curricular. Brasília, 2017. Disponível em: http:// basenacionalcomum.mec.gov.br/. Acesso em: 10 de Junho de 2021.

COSTA, A C. Psicopedagogia \& Psicomotricidade. Petrópolis: Vozes, 2001.

DERDYK, E. Formas de pensar o desenho: desenvolvimento do grafismo infantil. São Paulo: Panda Educação, 2020.

DUZZI, B. H. M.; RODRIGUES, D. das S. \& CIASCA, M. S. Percepção de professores sobre a relação entre desenvolvimento das habilidades psicomotoras e aquisição da escrita. Revista de Psicopedagogia, São Paulo, 2013, v. 30, n. 92, p. 121-128.

Fases do Desenvolvimento da Preensão do Lápis. Criando com Apego, 2021. Disponível em: https://www.criandocomapego.com/fases-do-desenvolvimento-da- preensao-do-lapis/. Acesso em: 14 de Junho de 2021.

FERNANDES, J. M. G. A.; GUTIERRES FILHO, P. J. B. Psicomotricidade: abordagens emergentes. Barueri: Manole, 2012. E-book.

FERNÁNDEZ, A. A inteligência aprisionada. Porto Alegre: Artes Médicas, 1991.

FONSECA, V. Desenvolvimento psicomotor e aprendizagem. Porto Alegre: Artmed, 2008. E-book.

FREIRE, J. B. De corpo e alma: o discurso da motricidade. São Paulo: Summus, 1991.

FREIRE, R. A. M. \& GERMANO, F. S. M. A Psicomotricidade como alicerce no desenvolvimento da leitura e da escrita. Interdisciplinary Scientific Journal, n. 6, v. 5, article n. 24, December 2018.

GONÇALVES, F. A. A Neurociência sob o olhar da Psicomotricidade. São Paulo: Cultural, 2019.

GONÇALVES, F. A. Caderno de Escrita Infantil: progressão grafomotoras para a aprendizagem da escrita. Ed. Cultural JR: Cajamar, 2014.

GONÇALVES, F. A. Do andar ao escrever: um caminho psicomotor. Cajamar: Cultural TBL, 2009.

GRASSI, T. M. Psicopedagogia: um olhar, uma escuta. Curitiba: InterSaberes, 2013.

KISHIMOTO, T. M. Jogo, Brinquedo, Brincadeira e a Educação. São Paulo: Cortez, 2011.

OLIVEIRA, M. Â. C. Psicopedagogia: a instituição educacional em foco. Curitiba: InterSaberes, 2014.

VYGOTSKY, L. S. A formação social da mente. São Paulo: Martins Fontes, 1998. 